\section{(1)}

CrossMark

\title{
Defective bacterial phagocytosis is associated with dysfunctional mitochondria in COPD macrophages
}

\author{
Kylie B.R. Belchamber (1) ${ }^{1}$, Richa Singh ${ }^{1}$, Craig M. Batista ${ }^{1}$, Moira K. Whyte ${ }^{2}$, \\ David H. Dockrell ${ }^{2}$, lain Kilty ${ }^{3}$, Matthew J. Robinson", Jadwiga A. Wedzicha', \\ Peter J. Barnes ${ }^{1}$ and Louise E. Donnelly ${ }^{1}$ on behalf of the COPD-MAP \\ consortium
}

Affiliations: ${ }^{1}$ Airway Disease, National Heart and Lung Institute, Imperial College London, London, UK. ${ }^{2} \mathrm{MRC}$ Centre for Inflammation Research, University of Edinburgh, Edinburgh, UK. ${ }^{3}$ Inflammation and Immunology Research Unit, Pfizer Inc, Cambridge, MA, USA. ${ }^{4}$ Medlmmune, Cambridge, UK.

Correspondence: Louise E. Donnelly, National Heart and Lung Institute, Guy Scadding Building, Dovehouse Street, London, SW3 6LY, UK. E-mail: L.donnelly@imperial.ac.uk

@ERSpublications

Defective phagocytosis in COPD macrophages is worsened by oxidative stress and is linked to altered mitochondrial function. http://bit.ly/2JBeOlw

Cite this article as: Belchamber KBR, Singh R, Batista CM, et al. Defective bacterial phagocytosis is associated with dysfunctional mitochondria in COPD macrophages. Eur Respir J 2019; 54: 1802244 [https://doi.org/10.1183/13993003.02244-2018].

ABSTRACT Increased reactive oxygen species (ROS) have been implicated in the pathophysiology of chronic obstructive pulmonary disease (COPD). This study examined the effect of exogenous and endogenous oxidative stress on macrophage phagocytosis in patients with COPD.

Monocyte-derived macrophages (MDMs) were generated from non-smoker, smoker and COPD

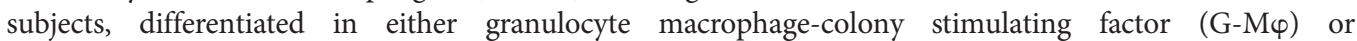
macrophage-colony stimulating factor $(\mathrm{M}-\mathrm{M} \varphi)$. Alveolar macrophages were isolated from lung tissue or bronchoalveolar lavage fluid. Macrophages were incubated in $\pm 200 \mu \mathrm{M} \mathrm{H}_{2} \mathrm{O}_{2}$ for $24 \mathrm{~h}$, then exposed to fluorescently labelled Haemophilus influenzae or Streptococcus pneumoniae for $4 \mathrm{~h}$, after which phagocytosis, mitochondrial ROS (mROS) and mitochondrial membrane potential $(\Delta \Psi \mathrm{m})$ were measured.

Phagocytosis of bacteria was significantly decreased in both G-M $\varphi$ and $M-M \varphi$ from COPD patients compared with from non-smoker controls. In non-smokers and smokers, bacterial phagocytosis did not alter mROS or $\Delta \Psi \mathrm{m}$; however, in COPD, phagocytosis increased early mROS and decreased $\Delta \Psi \mathrm{m}$ in both $\mathrm{G}-\mathrm{M} \varphi$ and $\mathrm{M}-\mathrm{M} \varphi$. Exogenous oxidative stress reduced phagocytosis in non-smoker and COPD alveolar macrophages and non-smoker MDMs, associated with reduced mROS production.

COPD macrophages show defective phagocytosis, which is associated with altered mitochondrial function and an inability to regulate mROS production. Targeting mitochondrial dysfunction may restore the phagocytic defect in COPD. 


\section{Introduction}

Chronic obstructive pulmonary disease (COPD) comprises three pathological conditions: emphysema, chronic bronchitis and small airways disease [1]. COPD is characterised by a progressive decline in lung function that can be worsened by exacerbations, leading to hospital admissions, morbidity and mortality [2-4]. In more developed nations, cigarette smoking induces inflammation and increased oxidative stress in the lungs, and is a major contributor to disease pathophysiology [5].

The lung microbiome in COPD patients is altered compared to that of healthy individuals, with colonisation of the lower respiratory tract with disease-specific microorganisms, including Haemophilus influenzae and Streptococcus pneumoniae [6]. These bacteria, together with viruses and other microorganisms, may drive exacerbations of COPD, which are associated with accelerated disease progression and worse clinical prognosis [2].

Alveolar macrophages contribute $90 \%-95 \%$ of cells found in bronchoalveolar lavage fluid and are highly phagocytic. Their main function is the removal of pathogens, including microorganisms and apoptotic cells, via phagocytosis and the regulation of inflammation [7]. However, in COPD, alveolar macrophages show defective phagocytosis of bacteria, fungal spores and apoptotic epithelial cells [8-10]. Monocyte-derived macrophages (MDMs) are used as a model of alveolar macrophages, and also carry the defect in phagocytosis observed in COPD [11]. Different macrophage phenotypes can be generated by incubating monocytes with specific growth factors to represent the heterogeneous populations of macrophages found in tissue, including the lungs. Granulocyte macrophage-colony stimulating factor (GM-CSF) and macrophage-colony stimulating factor (M-CSF) have been used to generate macrophage phenotypes with differing inflammatory profiles and as such provide a useful model for the study of macrophage phenotypes in COPD [11, 12]. There is increasing evidence from in vivo models that, although tissue-resident macrophages play a key role in lung immunity, during inflammation monocytes are recruited to the lungs, and these monocytes then differentiate into macrophages to increase the macrophage pool $[13,14]$. There is a 20 -fold increase in macrophage numbers in the lungs of COPD patients with severe emphysema [15] and increased numbers in bronchoalveolar lavage fluid and sputum of patients with less severe disease [16], indicating that monocyte recruitment is a potential source of macrophages in the lung during disease and that the study of MDMs is relevant in COPD.

Mitochondria function as cellular powerhouses, producing ATP via the electron transport chain. They are also important in intracellular calcium regulation, apoptosis and controlling the innate immune system [17]. Exposure of macrophages to cellular stress, such as cigarette smoke, biomass fuels or pollution, alters their mitochondrial function [18]. In COPD, mitochondria have been shown to be dysfunctional in airway smooth muscle cells $[19,20]$ and skeletal muscle [21, 22]. The mitochondria in these tissues show excessive mitochondrial reactive oxygen species (mROS) production, which is normally counteracted by antioxidants and enzymes [23, 24].

The defects seen in macrophage phagocytosis in COPD could be exacerbated by exogenous oxidative stress such as cigarette smoke and ROS, and lead to defective mitochondrial function, as observed in airway smooth muscle cells from these patients [19]. We therefore studied the effects of exogenous oxidative stress on phagocytosis and mitochondrial function, using both GM-CSF-differentiated (G-M $\varphi$ ) and $\mathrm{M}$-CSF-differentiated $(\mathrm{M}-\mathrm{M} \varphi) \mathrm{MDMs}$ and lung-derived macrophages from COPD patients in comparison with cells from age-matched healthy non-smokers and smokers without COPD, to determine whether mitochondrial dysfunction is associated with defective phagocytosis.

\section{Methods}

\section{Subject selection}

COPD patients were recruited from the UK Medical Research Council (MRC) COPD-MAP consortium of Global Initiative for Chronic Obstructive Lung Disease (GOLD) stage II/III patients. Control subjects included healthy non-smokers and smokers without COPD after screening. All subjects gave written informed consent prior to the start of the study. The study was approved by London-Hampstead National Research Ethics Committee (13/LO/1403) and the London-Chelsea National Research Ethics Committee (09/H0801/85). Subject demographics are presented in tables $1-3$. There was no difference in smoking history between smokers and COPD patients. Data on whether patients were current or ex-smokers were not available for this study. COPD patients had significantly worse lung function compared to controls. Patients continued to take their maintenance therapy, including long-acting anti-muscarinic agents, long-acting $\beta_{2}$-adrenergic agonists and inhaled corticosteroids.

\section{Macrophage isolation}

MDMs were generated from monocytes isolated from peripheral blood mononuclear cells using a Percoll gradient and adherence technique, followed by culture for 12 days in $2 \mathrm{ng} \cdot \mathrm{mL}^{-1} \mathrm{GM}-\mathrm{CSF}$ (cat. no. 
TABLE 1 Subject demographics for validating the use of the MDM model

\begin{tabular}{lccc} 
& Non-smoker & Smoker & COPD \\
\hline Subjects $\mathbf{n}$ & 17 & 16 & 17 \\
Age years & $61 \pm 3$ & $57 \pm 3$ & $60 \pm 2$ \\
Pack years & 0 & $32 \pm 10^{*}$ & $30 \pm 3^{* *}$ \\
FEV 1 L & $3.2 \pm 0.3$ & $2.9 \pm 0.4$ & $1.7 \pm 0.2^{* *}$ \\
FEV $\%$ predicted & $109 \pm 6$ & $92 \pm 4$ & $68 \pm 3^{* * *}$ \\
FVC L & $3.7 \pm 0.3$ & $3.7 \pm 0.4$ & $2.7 \pm 0.3$ \\
FEV 1 FVC & $0.80 \pm 0.02$ & $0.76 \pm 0.03$ & $0.69 \pm 0.04^{*}$
\end{tabular}

Data are presented as mean \pm SEM, unless otherwise indicated. MDM: monocyte-derived macrophages; COPD: chronic obstructive pulmonary disease; FEV1: forced expiratory volume in $1 \mathrm{~s}$; FVC: forced vital capacity. ${ }^{*}: p<0.05$; $^{* *}: p<0.01$ non-smoker versus smoker/COPD; ${ }^{* * *}: p<0.001$ COPD versus non-smoker/smoker.

7954-GM-059/CF, Bio-Techne, Abingdon, UK) to generate G-M $\varphi$ or $100 \mathrm{ng} \cdot \mathrm{mL}^{-1} \mathrm{M}-\mathrm{CSF}$ (cat. no. 216-MC-500, Bio-Techne) to generate $\mathrm{M}-\mathrm{M} \varphi$ as described previously [11]. All the MDMs used in this study were derived from freshly isolated monocytes. Macrophages were seeded at $0.5 \times 10^{6}$ cells per well in a 24-well plate. Alveolar macrophages were isolated from bronchoalveolar lavage fluid as described previously [25]. Lung tissue macrophages were isolated from lung parenchyma as described previously [26]. Lung tissue used in this study was assessed as being non-cancerous by the pathologist and from samples obtained during tissue resection for lung cancer or emphysema.

\section{Bacteria}

Serotype 14 S. pneumoniae (NCTC 11902, National Collection of Type Cultures) was grown as previously described [27]. Non-typeable H. influenzae (NCTC 1269, National Collection of Type Cultures) was cultured on chocolate agar overnight and then grown to an optical density at $600 \mathrm{~nm}$ of 0.6 in brain heart infusion (cat. no. CM1135, Oxoid Ltd, Basingstoke, UK) supplemented with 20\% (volume/volume) fetal calf serum (cat. no. FB-1001/500, Biosera, Heathfield, UK), $20 \mu \mathrm{g} \cdot \mathrm{mL}^{-1}$ NAD (cat. no. NAD-100RO, Sigma-Aldrich Company Ltd, Dorset, UK) and $10 \mu \mathrm{g} \cdot \mathrm{mL}^{-1}$ heme (cat. no. H9039, Sigma-Aldrich Company Ltd). Bacteria were not opsonised. Heat-killed bacteria were generated by incubation at $65^{\circ} \mathrm{C}$ for $10 \mathrm{~min}$ as described previously [25].

\section{Fluorescent labelling of heated-killed bacteria}

Bacterial cultures were fluorescently labelled using AlexaFluor 405 NHS ester (cat. no. A30000, Life Technologies, Paisley, UK) or AlexaFluor $488 \mathrm{NHS}$ ester $\left(1 \mathrm{mg} \cdot \mathrm{mL}^{-1}\right.$ in dimethyl sulfoxide (DMSO), cat. no. A20100, Life Technologies) and incubated overnight. Labelled bacteria were washed repeatedly in PBS to remove unbound label, then resuspended in PBS and stored at $-20^{\circ} \mathrm{C}$.

\section{Bacterial phagocytosis}

Fluorescent bacterial stocks were sonicated and added to macrophages at $1.5 \times 10^{10} \mathrm{CFU} \cdot \mathrm{mL}^{-1}$ for H. influenzae and $1.7 \times 10^{8} \mathrm{CFU} \cdot \mathrm{mL}^{-1}$ for $S$. pneumoniae, and incubated at $37^{\circ} \mathrm{C}$ for $4 \mathrm{~h}$. For flow

TABLE 2 Subject demographics for examining the effect of exogenous stress on macrophage phagocytosis

\begin{tabular}{lcc} 
& Healthy & COPD \\
\hline Subjects $n$ & 13 & 7 \\
Age years & $62 \pm 3$ & $68 \pm 4$ \\
Pack years & $20 \pm 5$ & $32 \pm 4$ \\
FEV1 L & $2.7 \pm 0.2$ & $1.7 \pm 0.2^{* * *}$ \\
FEV1 \% predicted & $94 \pm 4$ & $70 \pm 8^{*}$ \\
FVC L & $3.7 \pm 0.2$ & $3.1 \pm 0.2$ \\
FEV1/FVC & $0.73 \pm 0.03$ & $0.56 \pm 0.05^{* *}$ \\
\hline
\end{tabular}

Macrophages were isolated from tissue resection $(n=12)$ or bronchoalveolar lavage $(n=8)$. Data are presented as mean \pm SEM, unless otherwise indicated. COPD: chronic obstructive pulmonary disease; FEV1: forced expiratory volume in $1 \mathrm{~s}$; FVC: forced vital capacity. ${ }^{*}: p<0.05 ;{ }^{* *}: p<0.01 ;{ }^{* *}: p<0.001$ healthy versus COPD. 


\begin{tabular}{|c|c|c|c|}
\hline & Non-smoker & Smoker & COPD \\
\hline Sex (M:F) & $10: 7$ & $13: 3$ & $10: 7$ \\
\hline Age years & $61 \pm 2$ & $63 \pm 2$ & $71 \pm 3$ \\
\hline Pack years & 0 & $29 \pm 4 * * *$ & $47 \pm 7 * * *$ \\
\hline FEV 1 L & $2.9 \pm 0.3$ & $3.0 \pm 0.2^{\# \# \#}$ & $1.5 \pm 0.2^{* * *}$ \\
\hline FEV $1 \%$ predicted & $100 \pm 5$ & $94 \pm 3^{\# \# \#}$ & $55 \pm 5^{* * *}$ \\
\hline FVC L & $3.9 \pm 0.3$ & $4.2 \pm 0.3^{\#}$ & $2.8 \pm 0.3^{*}$ \\
\hline FEV $1 / F V C$ & $0.76 \pm 0.02$ & $0.73 \pm 0.02^{\# \# \#}$ & $0.52 \pm 0.04^{* * *}$ \\
\hline
\end{tabular}

Data are presented as mean \pm SEM, unless otherwise indicated. COPD: chronic obstructive pulmonary disease; $M$; male; $F$; female; FEV1: forced expiratory volume in $1 \mathrm{~s}$; FVC: forced vital capacity. *: $p<0.05$; ***: $p<0.001$ non-smoker versus smoker/COPD; ${ }^{\#}: p<0.05 ;{ }^{\# \# \#}: p<0.001$ smoker versus COPD.

cytometry, cells were washed with PBS to remove free bacteria, and cells were dissociated from the plate using cell dissociation media and vigorous pipetting. Cells were transferred to fluorescence-activated cell sorting (FACS) tubes, centrifuged, resuspended in $200 \mu \mathrm{L}$ PBS and analysed by flow cytometry using a BD FACS Canto II (BD Biosciences, Wokingham, UK), in the pacific blue channel. Data were acquired using FACS DIVA software and subsequently analysed using Flowjo software (Treestar, Ashland, OR, USA). For plate reader assays, cells were washed with PBS and fluorescence of extracellular particles was quenched by adding Trypan blue (2\% weight/volume) for $1 \mathrm{~min}$. Excess fluid was removed and fluorescence determined using excitation at $\lambda 480 \mathrm{~nm}$ and emission at $\lambda 520 \mathrm{~nm}$. The relative amount of bacteria phagocytosed is reported as relative fluorescent units (RFU).

\section{Measurement of mROS using MitoSOX assay}

Post phagocytosis, wells were washed with Hanks' balanced salt solution (HBSS) (calcium free) and $5 \mu \mathrm{M}$ MitoSOX dye (cat. no. M36008, Thermo Fisher, Loughborough, UK) added as per manufacturer's instructions. Cells were incubated for $30 \mathrm{~min}$ at $37^{\circ} \mathrm{C}$, then washed with HBSS containing calcium $\left(0.185 \mathrm{~g} \cdot \mathrm{L}^{-1}\right)$. Cells were dissociated from the plate using cell dissociation media and vigorous pipetting. Cells were transferred to FACS tubes, centrifuged, resuspended in $200 \mu \mathrm{L}$ HBSS and analysed by flow cytometry using a BD FACS Canto II, in the phycoerythrin (PE) channel, and bacteria were measured in the pacific blue channel.

\section{Measurement of mitochondrial membrane potential using JC-1}

To measure mitochondrial membrane potential $(\Delta \Psi \mathrm{m})$, a tetrachloro-1,1',3,3'-tetraethylbenzimidazolylcarbocyanine iodide (JC-1) assay was performed post phagocytosis as per manufacturer's instructions (cat. no. M43152, Thermo Fisher). Briefly, cells in a 24-well plate were washed with PBS and replaced with $500 \mu \mathrm{L}$ warm cell culture media. $50 \mu \mathrm{M}$ carbonyl cyanide $m$-chlorophenyl hydrazone (CCCP) was added to the positive control well and the plate was incubated for $5 \mathrm{~min}$ at $37^{\circ} \mathrm{C} .2 \mu \mathrm{M} \mathrm{JC}-1$ dye was then added to all wells for a further $25 \mathrm{~min}$ at $37^{\circ} \mathrm{C}$, after which the cells were washed with PBS. Cells were dissociated from the plate using cell dissociation media and vigorous pipetting. Cells were transferred to FACS tubes, centrifuged, resuspended in $200 \mu \mathrm{L}$ PBS and analysed by flow cytometry using a BD FACS Canto II, in the $\mathrm{PE}$ and fluorescein isothiocyanate channel, and bacteria were measured in the pacific blue channel.

\section{Confocal microscopy}

MDMs were cultured on Ibidi $\mu$ chamber slides (Gräfelfing, Germany) and phagocytosis performed. Cells were fixed with $4 \%$ (volume/volume) paraformaldehyde. Nuclei were stained with 4',6-diamidino-2-phenylindole (DAPI) and cytoplasm with cell tracker red. Slides were imaged on a Zeiss LSM-510 inverted confocal microscope (Carl Zeiss, Oberkochen, Germany) and analysed using FIJI software [28].

\section{Cell viability}

Cell viability was measured by incubating MDMs in $0.1 \%$ (weight/volume) 3-(4,5-dimethylthiazol-2-yl)2,5 diphenyltetrazolium bromide (MTT) at $37^{\circ} \mathrm{C}$ for $30 \mathrm{~min}$ before removing MTT and adding DMSO to lyse the cells. Absorbance was measured at $\lambda 570 \mathrm{~nm}$ using a SpectraMax photometer (Molecular Devices, Wokingham, UK) to quantify cell viability. Each treated well was normalised to the average of the non-treated control, which was set to $100 \%$ viability. 


\section{Statistical analysis}

Data are presented as mean \pm SEM or as individual data points, and significance was analysed using either a Wilcoxon matched pairs signed rank test for comparison of two variables or Kruskal-Wallis test for comparison of multiple variables with post hoc Dunn's test using GraphPad Prism 5 software (GraphPad, San Diego, CA, USA).

\section{Results}

Correlation between phagocytosis of alveolar macrophages and MDMs

In order to further validate the use of MDMs to assess the phagocytic capacity of macrophages, alveolar macrophages and MDMs were isolated from the same patient, and phagocytic assays were performed. Significant correlations were observed in the phagocytic capacity of alveolar macrophages and either $\mathrm{M}-\mathrm{M} \varphi$ or $\mathrm{G}-\mathrm{M} \varphi$ for both $H$. influenzae ( $\mathrm{r}=0.63$ and 0.71 respectively, figure $1 \mathrm{a}, \mathrm{b}$ ) and $S$. pneumoniae $(\mathrm{r}=0.40$ and 0.60 respectively, figure $1 \mathrm{c}, \mathrm{d})$. Internalisation of bacteria was confirmed by confocal
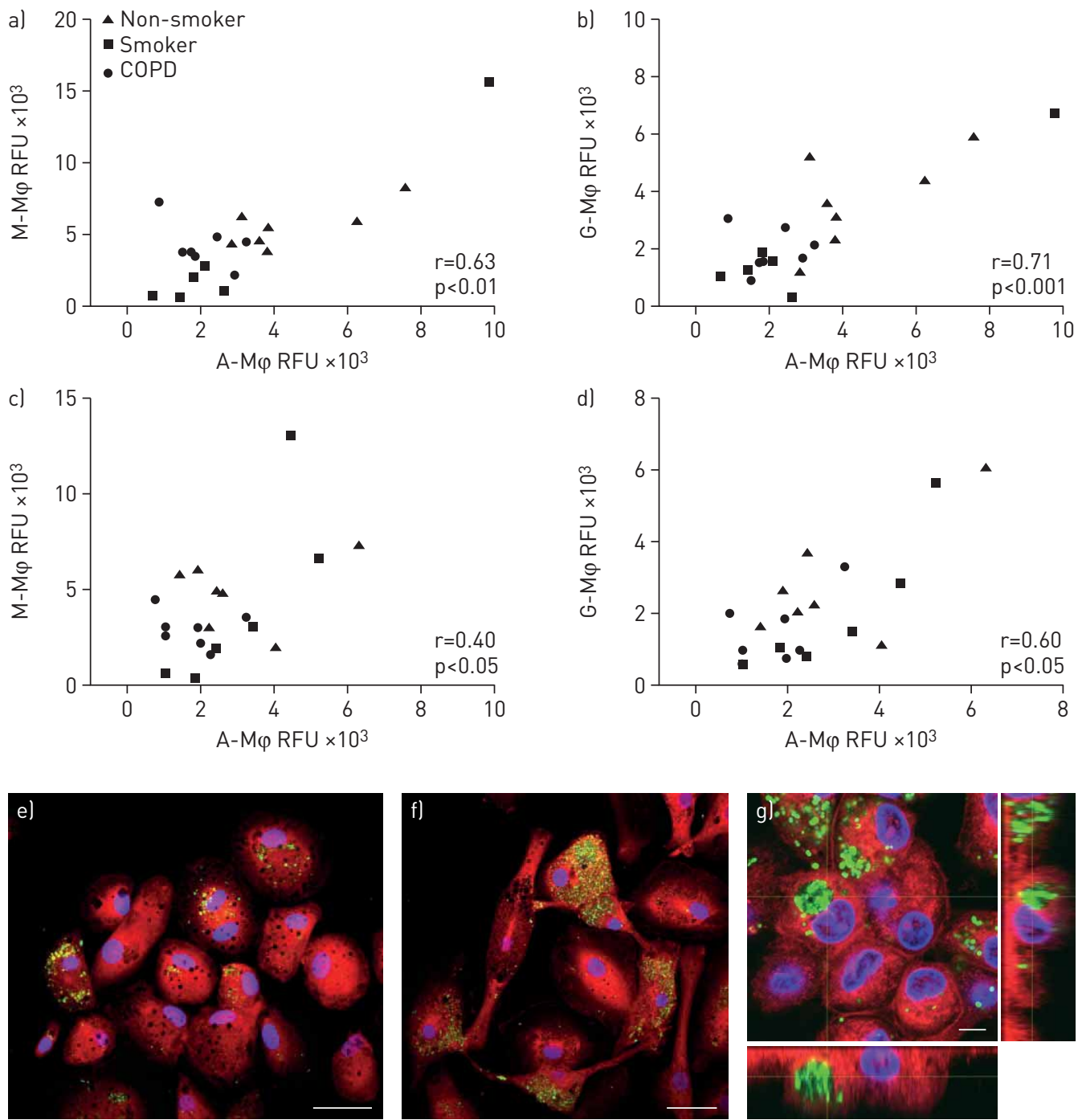

FIGURE 1 Correlations of phagocytosis of respiratory pathogens between alveolar macrophages and monocyte-derived macrophages from the same subjects. a-d) Non-smoker ( $n=7)$, smoker ( $n=7)$ and chronic obstructive pulmonary disease (COPD) $(n=6)$ alveolar macrophages $(A-M \varphi)$ and macrophages differentiated in either granulocyte macrophage-colony stimulating factor $(G-M \varphi)$ or macrophage-colony stimulating factor $(\mathrm{M}-\mathrm{M} \varphi)$ were isolated from the same subject, co-cultured with fluorescently labelled Haemophilus influenzae (a, b) or Streptococcus pneumoniae (c, d) bacteria for $4 \mathrm{~h}$ and phagocytosis measured by relative fluorescence units (RFU). Data are individual data points and correlation ( $r$ ) is reported as Spearman's rank coefficient. $e, f)$ Confocal microscopic images of samples confirm internalisation of bacteria in $G-M \varphi(e)$ and $M-M \varphi(f)$,

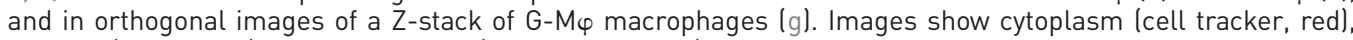
nucleus (blue, DAPI) and $H$. influenzae (green, Alexa-488). Scale bars: $e=22 \mu \mathrm{m} ; f=35 \mu \mathrm{m} ; g=10 \mu \mathrm{m}$. 
microscopy (figure 1e-g). From these data, the MDM model was used in future experiments for which alveolar macrophages were not available.

\section{Defective macrophage phagocytosis in COPD}

Experiments were performed in order to confirm previous data showing defective phagocytosis by COPD macrophages. Regardless of whether MDMs were differentiated with GM-CSF or M-CSF, there was a significant reduction in uptake of both $H$. influenzae and $S$. pneumoniae by COPD macrophages in comparison to healthy volunteer-derived cells $(\mathrm{p}<0.05)$, measured by median fluorescence intensity (MFI) (figure $2 \mathrm{~b}, \mathrm{~d}$ ). However, irrespective of subject group, $60 \%-80 \%$ of cells were capable of phagocytosis, measured by $\%$ macrophage phagocytosis (figure $2 \mathrm{a}, \mathrm{c}$ ). In addition, there were no differences between the ability of $\mathrm{G}-\mathrm{M} \varphi$ and $\mathrm{M}-\mathrm{M} \varphi$ to phagocytose, although $\mathrm{M}-\mathrm{M} \varphi$ displayed a trend for increased phagocytosis compared with $\mathrm{G}-\mathrm{M} \varphi$ from all subject groups.

\section{Exogenous oxidative stress on macrophage phagocytosis}

Alveolar macrophages and MDMs were exposed to $200 \mu \mathrm{M} \mathrm{H}_{2} \mathrm{O}_{2}$ for $24 \mathrm{~h}$, and phagocytosis measured by MFI. Pilot studies showed that $200 \mu \mathrm{M} \mathrm{H}_{2} \mathrm{O}_{2}$ was the maximal concentration to have no effect on cell viability (supplementary figure $\mathrm{S} 1$ ). Exposure of alveolar macrophages to $\mathrm{H}_{2} \mathrm{O}_{2}$ decreased phagocytosis of $H$. influenzae (non-smokers $\mathrm{p}<0.05, \mathrm{COPD} \mathrm{p}<0.05$, figure $3 \mathrm{a}$ ) and $S$. pneumoniae (non-smokers $\mathrm{p}<0.01$, figure $3 \mathrm{~b}$ ) in cells from non-smokers and COPD patients. Exposure of non-smoker $\mathrm{M}-\mathrm{M} \varphi$ and $\mathrm{G}-\mathrm{M} \varphi$ to $\mathrm{H}_{2} \mathrm{O}_{2}$ decreased phagocytosis of $H$. influenzae ( $\mathrm{p}<0.05$, figure $3 \mathrm{c}, \mathrm{e}$ ) and $S$. pneumoniae ( $<<0.05$, figure $3 \mathrm{~d}, \mathrm{f}$ ), while exposure of COPD $\mathrm{M}-\mathrm{M} \varphi$ and $\mathrm{G}-\mathrm{M} \varphi$ decreased phagocytosis of $S$. pneumoniae $(\mathrm{p}<0.05$, figure $3 \mathrm{~d}, \mathrm{f})$, but not $H$. influenzae ( $\mathrm{p}>0.05$, figure $3 c, e)$.

\section{Macrophage $m R O S$ in response to phagocytosis}

At baseline, mROS levels were similar in all cells from all subject groups irrespective of the differentiation process (table 4). Similarly phagocytosis of either H. influenzae or S. pneumoniae had no effect on mROS
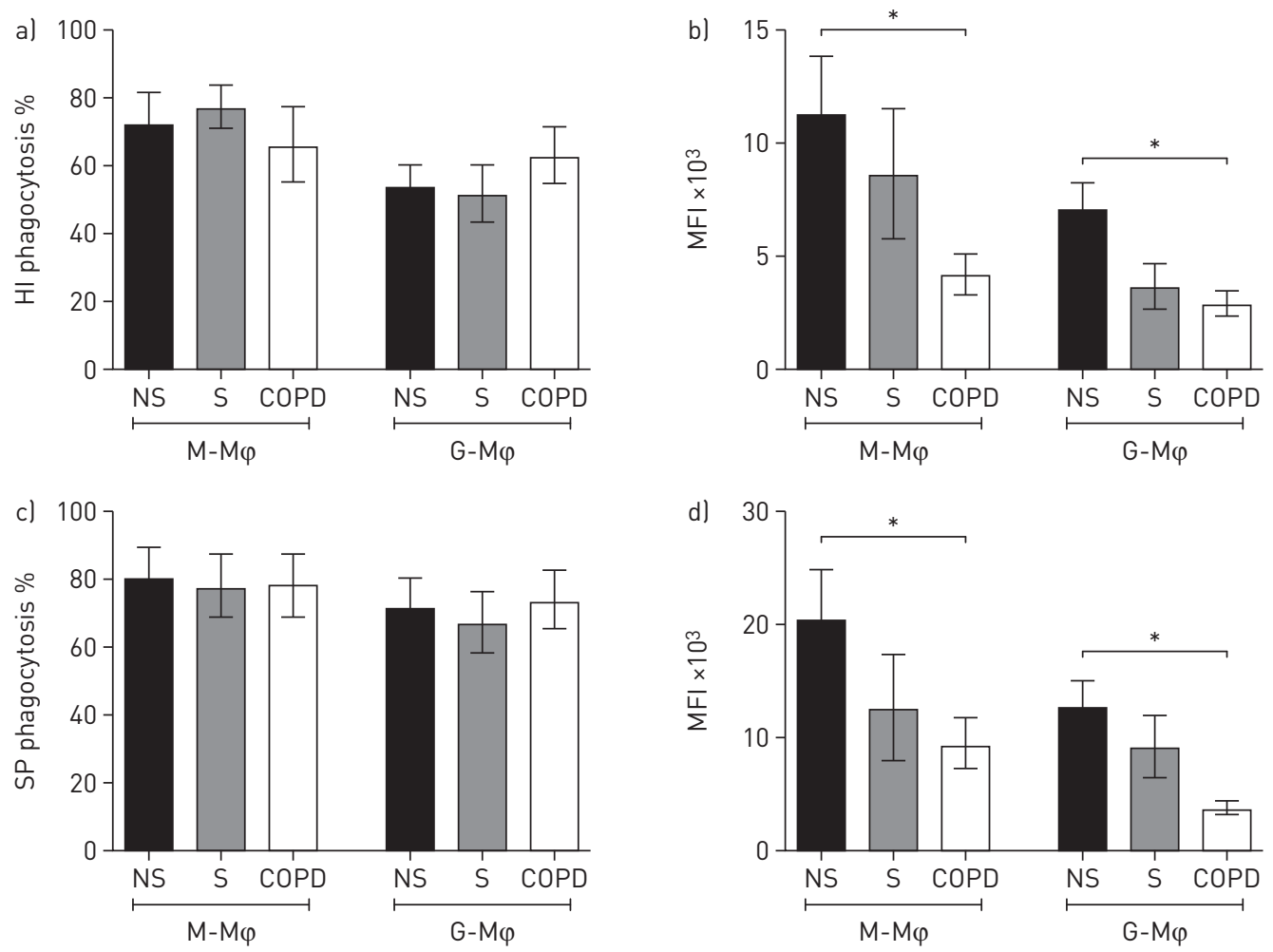

FIGURE 2 Internalisation of bacteria by macrophages from non-smokers (NS), smokers without chronic obstructive pulmonary disease (COPD) (S) and COPD patients. Macrophages differentiated in either granulocyte macrophage-colony stimulating factor $(G-M \varphi)$ or macrophage-colony stimulating factor $(M-M \varphi)$ isolated from study subjects were co-cultured with fluorescently labelled Haemophilus influenzae (HI) (a, b) or Streptococcus pneumoniae (SP) (c, d) bacteria for $4 \mathrm{~h}$, after which the percentage of cells that had undergone phagocytosis (a, c) and median fluorescence intensity (MFI) (b, d) were measured by flow cytometry. Data are presented as mean \pm SEM of 9-12 independent experiments. *: $p<0.05$ non-smoker versus COPD. 

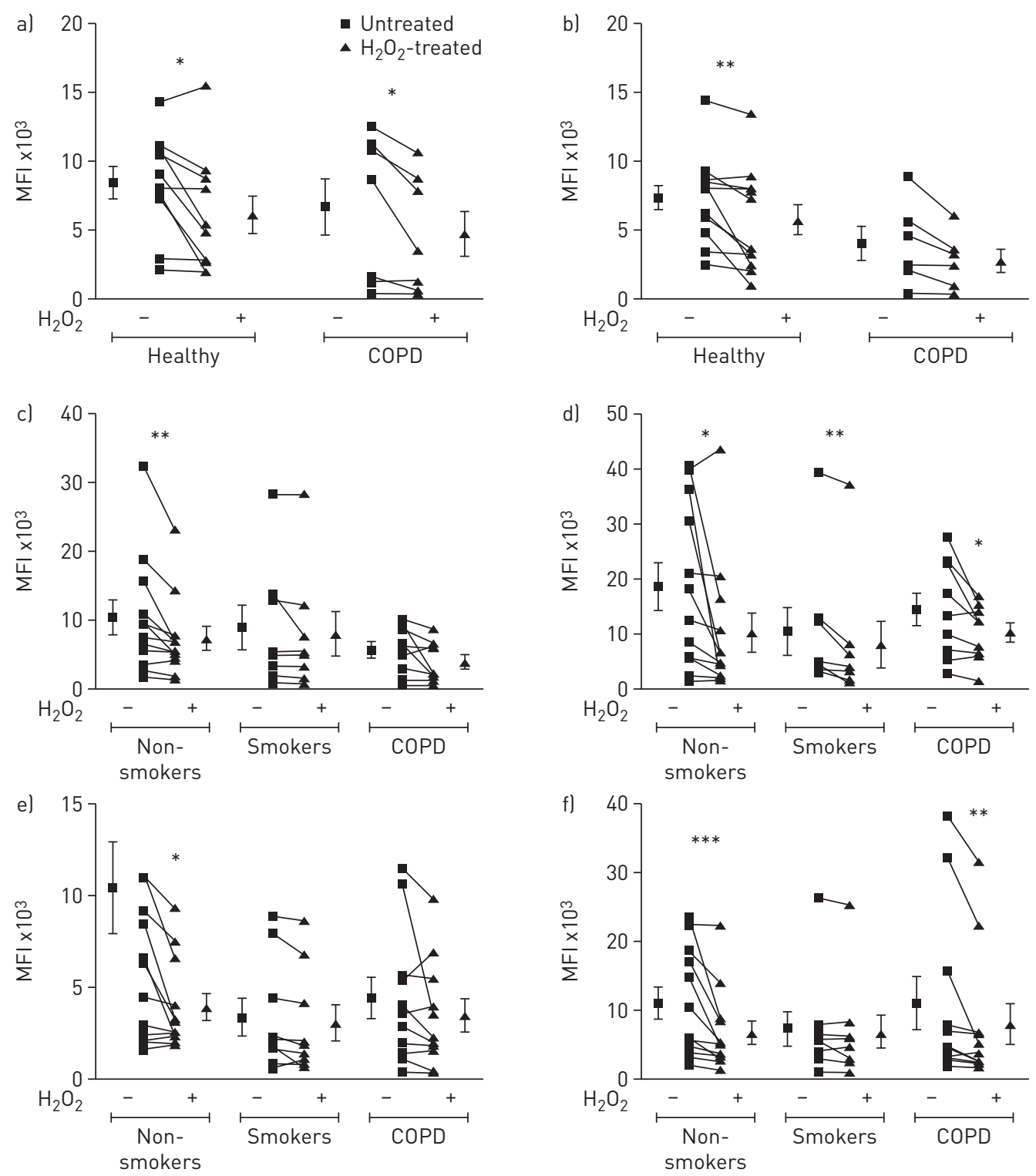

FIGURE 3 Exogenous oxidative stress decreases macrophage phagocytosis. Alveolar macrophages $\left(A-M_{\varphi}\right)$ $(a, b)$ isolated from healthy volunteers $(n=13)$ and patients with chronic obstructive pulmonary disease (COPD) $(\mathrm{n}=7)$ and macrophages differentiated in either macrophage-colony stimulating factor $(\mathrm{M}-\mathrm{M} \varphi)(\mathrm{c}, \mathrm{d})$ or granulocyte macrophage-colony stimulating factor $\left(G-M_{\varphi}\right)(e, f)$ isolated from non-smokers (n=12), smokers without COPD $(n=8-9)$ and COPD patients $(n=10-11)$ were left untreated or treated with $200 \mu \mathrm{M}$ hydrogen peroxide $\left(\mathrm{H}_{2} \mathrm{O}_{2}\right)$ for $24 \mathrm{~h}$, then co-cultured with fluorescently labelled Haemophilus influenzae $(\mathrm{a}, \mathrm{c}$, e) or Streptococcus pneumoniae $(b, d, f)$ bacteria for $4 \mathrm{~h}$, after which median fluorescence intensity (MFI) of phagocytosis was measured by flow cytometry. Data are presented as individual data points and as mean \pm SEM of untreated or $\mathrm{H}_{2} \mathrm{O}_{2}$-treated cells. ${ }^{*}$ : $\mathrm{p}<0.05 ;{ }^{* *}$ : $\mathrm{p}<0.01$; ${ }^{* * *}$ : $\mathrm{p}<0.001$ untreated versus $\mathrm{H}_{2} \mathrm{O}_{2}$.

levels in either G-M $\varphi$ or $\mathrm{M}-\mathrm{M} \varphi$ from non-smokers (figure $4 \mathrm{a}, \mathrm{b}$ ) or smokers without COPD (figure $4 \mathrm{c}, \mathrm{d}$ ). However, in COPD $\mathrm{M}-\mathrm{M} \varphi$, phagocytosis of both $H$. influenzae and $S$. pneumoniae led to a significant increase in mROS levels of $58 \%(\mathrm{p}<0.01)$ and $59 \%(\mathrm{p}<0.05)$ respectively (figure $4 \mathrm{e})$. In contrast, only phagocytosis of $H$. influenzae $(50 \%, \mathrm{p}<0.05)$, and not $S$. pneumoniae, increased mROS levels in COPD $\mathrm{G}-\mathrm{M} \varphi$ (figure $4 \mathrm{f}$ ).

We next measured $\Delta \Psi \mathrm{m}$ to determine whether this observation could be due to changes in mitochondrial function. At baseline, there was no difference in $\Delta \Psi \mathrm{m}$ between patient groups or macrophage phenotypes (table 4). After phagocytosis, there was no change in $\Delta \Psi \mathrm{m}$ in either $\mathrm{G}-\mathrm{M} \varphi$ or $\mathrm{M}-\mathrm{M} \varphi$ from non-smokers and smokers without COPD (figure $5 \mathrm{a}-\mathrm{d}$ ). In contrast, phagocytosis of $H$. influenzae, but not $S$. pneumoniae, caused a significant decrease in $\Delta \Psi \mathrm{m}$ in both $\mathrm{M}-\mathrm{M} \varphi(\mathrm{p}<0.01$, figure $5 \mathrm{e})$ and $\mathrm{G}-\mathrm{M} \varphi(\mathrm{p}<0.01$, figure $5 f)$ from COPD patients. The positive control CCCP reduced $\Delta \Psi \mathrm{m}$ in all cell types $(\mathrm{p}<0.001$, figure 5$)$. 
TABLE 4 Baseline values for $\mathrm{mROS}$ and $\Delta \Psi \mathrm{m}$

\begin{tabular}{|c|c|c|c|c|c|c|c|c|}
\hline & \multicolumn{4}{|c|}{ mROS } & \multicolumn{4}{|c|}{$\Delta \Psi \mathrm{m}$} \\
\hline & \multicolumn{2}{|c|}{$\mathrm{M}-\mathrm{M} \varphi$} & \multicolumn{2}{|c|}{$G-M_{\varphi}$} & \multicolumn{2}{|c|}{$M-M \varphi$} & \multicolumn{2}{|c|}{ G-M $\varphi$} \\
\hline & UT & $\mathrm{H}_{2} \mathrm{O}_{2}$ & UT & $\mathrm{H}_{2} \mathrm{O}_{2}$ & UT & $\mathrm{H}_{2} \mathrm{O}_{2}$ & UT & $\mathrm{H}_{2} \mathrm{O}_{2}$ \\
\hline Non-smoker & $2.06 \pm 0.4$ & $1.92 \pm 0.4$ & $2.34 \pm 0.4$ & $2.3 \pm 0.4$ & $1.09 \pm 0.06$ & $1.05 \pm 0.09$ & $1.39 \pm 0.09$ & $1.43 \pm 0.15$ \\
\hline Smoker & $2.13 \pm 0.6$ & $2.37 \pm 0.7$ & $2.27 \pm 0.5$ & $2.20 \pm 0.5$ & $1.08 \pm 0.07$ & $1.09 \pm 0.06$ & $1.15 \pm 0.07$ & $1.14 \pm 0.09$ \\
\hline COPD & $2.24 \pm 0.4$ & $1.81 \pm 0.4$ & $2.55 \pm 0.5$ & $2.42 \pm 0.5$ & $1.06 \pm 0.11$ & $1.02 \pm 0.10$ & $1.28 \pm 0.15$ & $1.29 \pm 0.12$ \\
\hline
\end{tabular}

Data are presented as mean \pm SEM. mROS: mitochondrial reactive oxygen species; $\Delta \Psi \mathrm{m}$ : mitochondrial membrane potential; $M-M \varphi$ : macrophage-colony stimulating factor-derived macrophages; G-M $\varphi$ : granulocyte macrophage-colony stimulating factor-derived macrophages; UT: untreated cells; $\mathrm{H}_{2} \mathrm{O}_{2}$ : cells treated with $200 \mathrm{mM}$ hydrogen peroxide for $24 \mathrm{~h}$; COPD: chronic obstructive pulmonary disease.

\section{Exogenous oxidative stress and mitochondrial function}

Having shown that exogenous oxidative stress impairs phagocytosis in cells from non-smokers and COPD patients, the effect on mitochondrial function was also investigated. At baseline, $\mathrm{H}_{2} \mathrm{O}_{2}$ had no effect on mROS or $\Delta \Psi \mathrm{m}$ in any cell type from any of the subjects used in this study (table 4). However, after phagocytosis, changes were observed. In $\mathrm{M}-\mathrm{M} \varphi$, non-smoker cells that had been exposed to $\mathrm{H}_{2} \mathrm{O}_{2}$ showed a decrease in mROS after phagocytosis of both $H$. influenzae $(\mathrm{p}<0.01$, figure $6 \mathrm{a})$ and $S$. pneumoniae $(\mathrm{p}<0.01$, figure $6 \mathrm{~b})$, while in COPD a decrease was also seen with both bacterial species $(\mathrm{p}<0.05$, figure $6 \mathrm{a}, \mathrm{b})$. In $\mathrm{G}-\mathrm{M} \varphi$, non-smoker cells that had been exposed to $\mathrm{H}_{2} \mathrm{O}_{2}$ showed a decrease in mROS after phagocytosis

FIGURE 4 Increased production of mitochondrial reactive oxygen species (mROS) in chronic obstructive pulmonary disease (COPD) macrophages in response to phagocytosis. Macrophages differentiated in either macrophage-colony stimulating factor $(M-M \varphi)(a, c, e)$ or granulocyte macrophage-colony stimulating factor $(G-M \varphi)(b, d, f)$ from non-smokers $(n=10, a, b)$, smokers without COPD ( $n=9-10$, $c, d)$ and COPD patients ( $n=13, e, f)$ were analysed for mROS levels after $4 \mathrm{~h}$ co-culture with fluorescently labelled Haemophilus influenzae (HI) or Streptococcus pneumoniae (SP). Data are normalised to untreated control (UT). *: $p<0.01 ;{ }^{* *}: p<0.01$ non-stimulated versus bacteria.
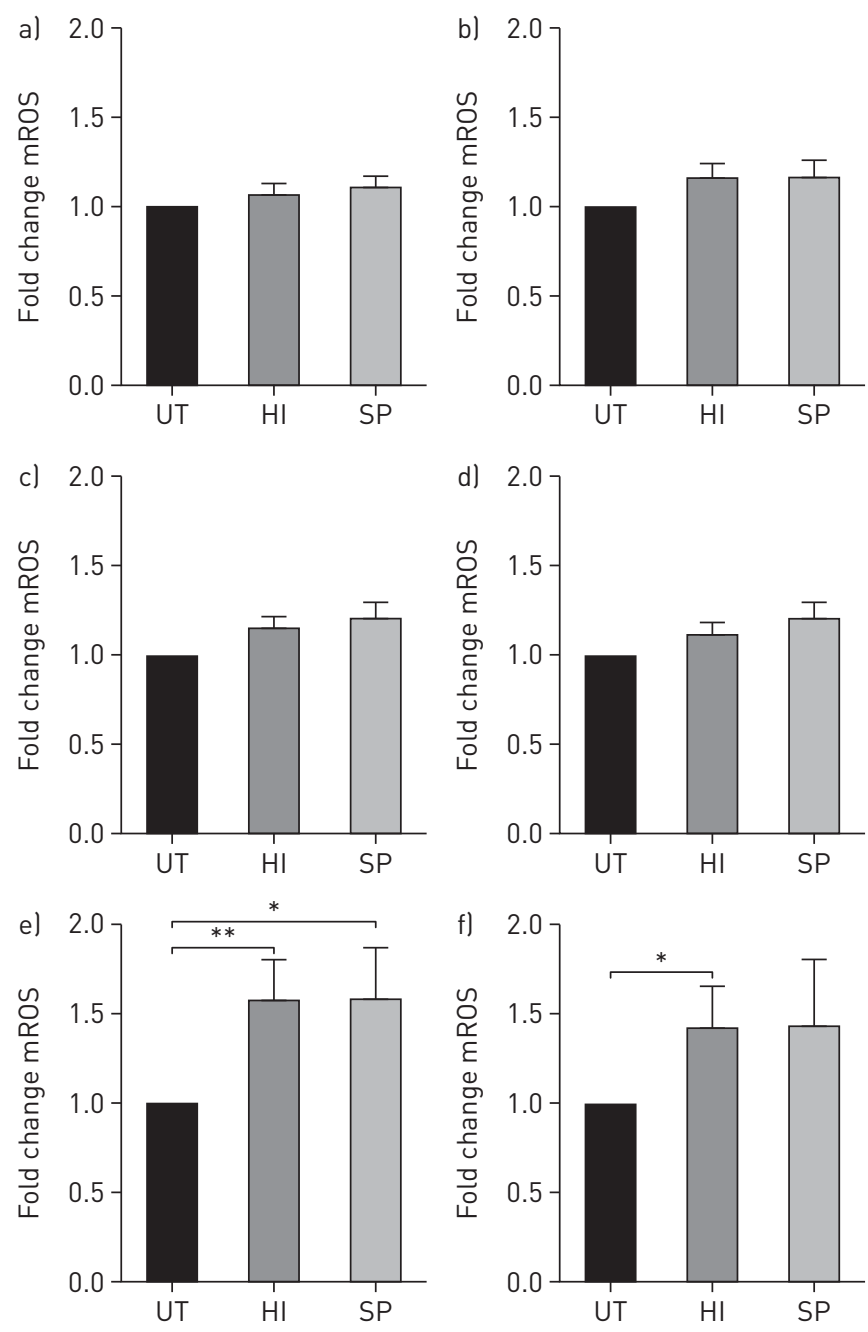

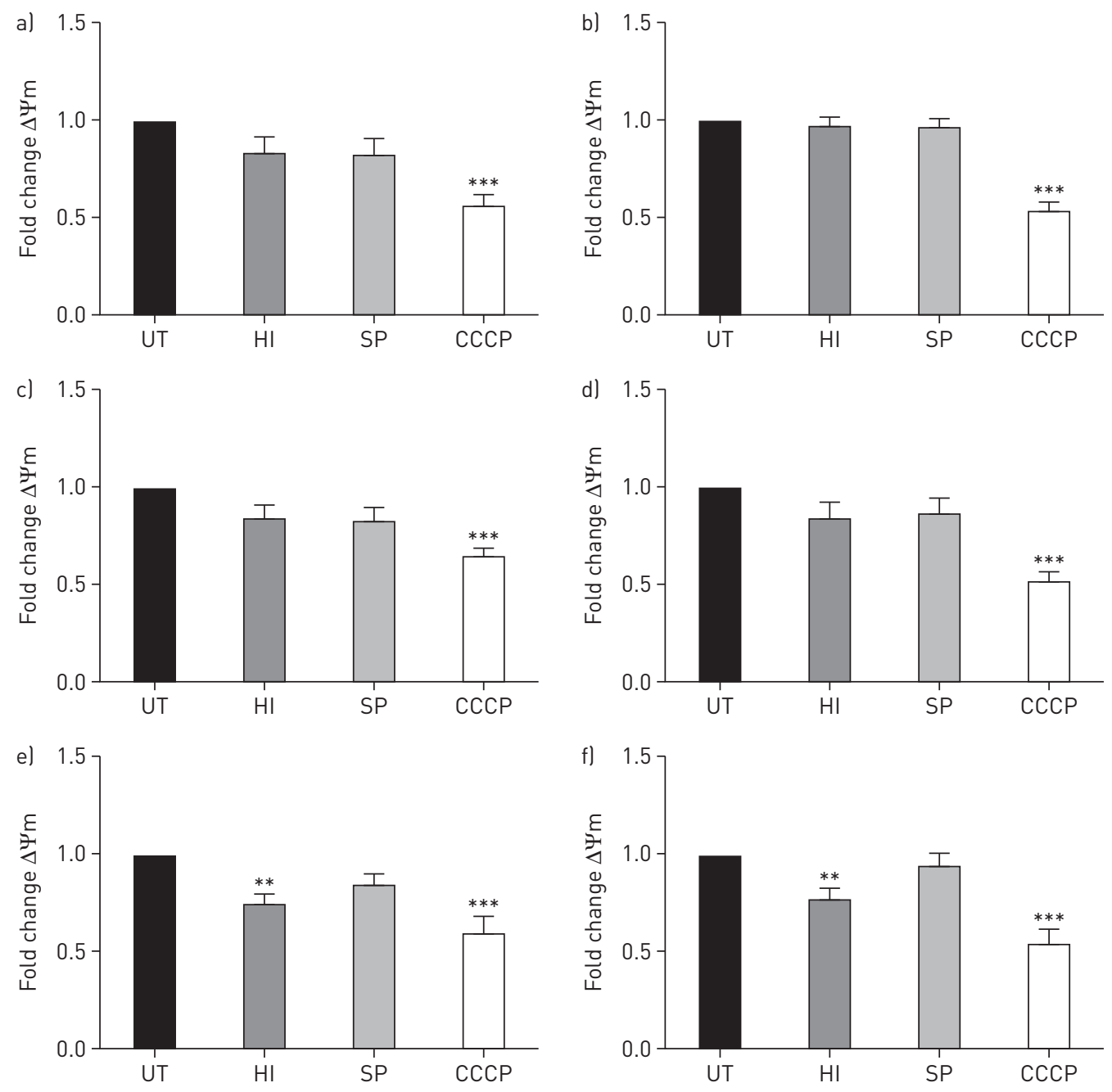

FIGURE 5 Decreased mitochondrial membrane potential $(\Delta \Psi \mathrm{m})$ in chronic obstructive pulmonary disease (COPD) macrophages in response to phagocytosis. Macrophages differentiated in either macrophage-colony stimulating factor $(M-M \varphi)(a, c, e)$ or granulocyte macrophage-colony stimulating factor $(G-M \varphi)(b, d, f)$ from non-smokers $(n=10, a, b)$, smokers without $\operatorname{COPD}(n=10, c, d)$ and $\operatorname{COPD}$ patients $(n=10, e, f)$ were analysed for $\Delta \Psi \mathrm{m}$ after $4 \mathrm{~h}$ co-culture with fluorescently labelled Haemophilus influenzae (HI) or Streptococcus pneumoniae (SP), with carbonyl cyanide $m$-chlorophenyl hydrazine (CCCP) acting as a positive control. Data show fold change from untreated control (UT). ${ }^{* *}: p<0.01 ;{ }^{* * *}: p<0.001$ versus non-stimulated.

of both $H$. influenzae $(\mathrm{p}<0.05$, figure $6 \mathrm{c})$ and $S$. pneumoniae $(\mathrm{p}<0.01$, figure $6 \mathrm{~d})$, while in smokers without COPD a decrease was also seen with both bacterial species $(\mathrm{p}<0.05$, figure $6 c, d)$. In COPD G-M $\varphi$, a decrease was seen with $S$. pneumoniae $(\mathrm{p}<0.01$, figure $6 \mathrm{~d}$ ) but did not reach significance in cells exposed to $H$. influenzae ( $\mathrm{p}=0.054)$. No effect of $\mathrm{H}_{2} \mathrm{O}_{2}$ and phagocytosis was seen on $\Delta \Psi \mathrm{m}$ in any cell type studied $(\mathrm{p}>0.05$, figure 7$)$.

\section{Discussion}

Alveolar macrophages are phagocytic cells that patrol the airways and removed inhaled particulates and microorganisms [29]. However, COPD macrophages phagocytose bacteria poorly, which could contribute to bacterial colonisation of the lungs, and lead to worsening of symptoms and lung function decline $[8,11]$. MDMs have been shown to be an effective model of alveolar macrophages, because they share the functional defect in phagocytosis and are more easily obtainable than alveolar macrophages [11]. In this study, we generated MDMs by differentiating monocytes in GM-CSF (G-M $\varphi$ ) or M-CSF (M-M $\varphi$ ) to investigate two macrophage phenotypes that have been characterised by others previously [30, 31], and confirmed key data using alveolar macrophages isolated from lung tissue [32].

In the present study, we have demonstrated that in both $\mathrm{G}-\mathrm{M} \varphi$ and $\mathrm{M}-\mathrm{M} \varphi$ phenotypes there was a significant decrease in phagocytosis of the respiratory pathogens $H$. influenzae $(\mathrm{p}<0.05)$ and 

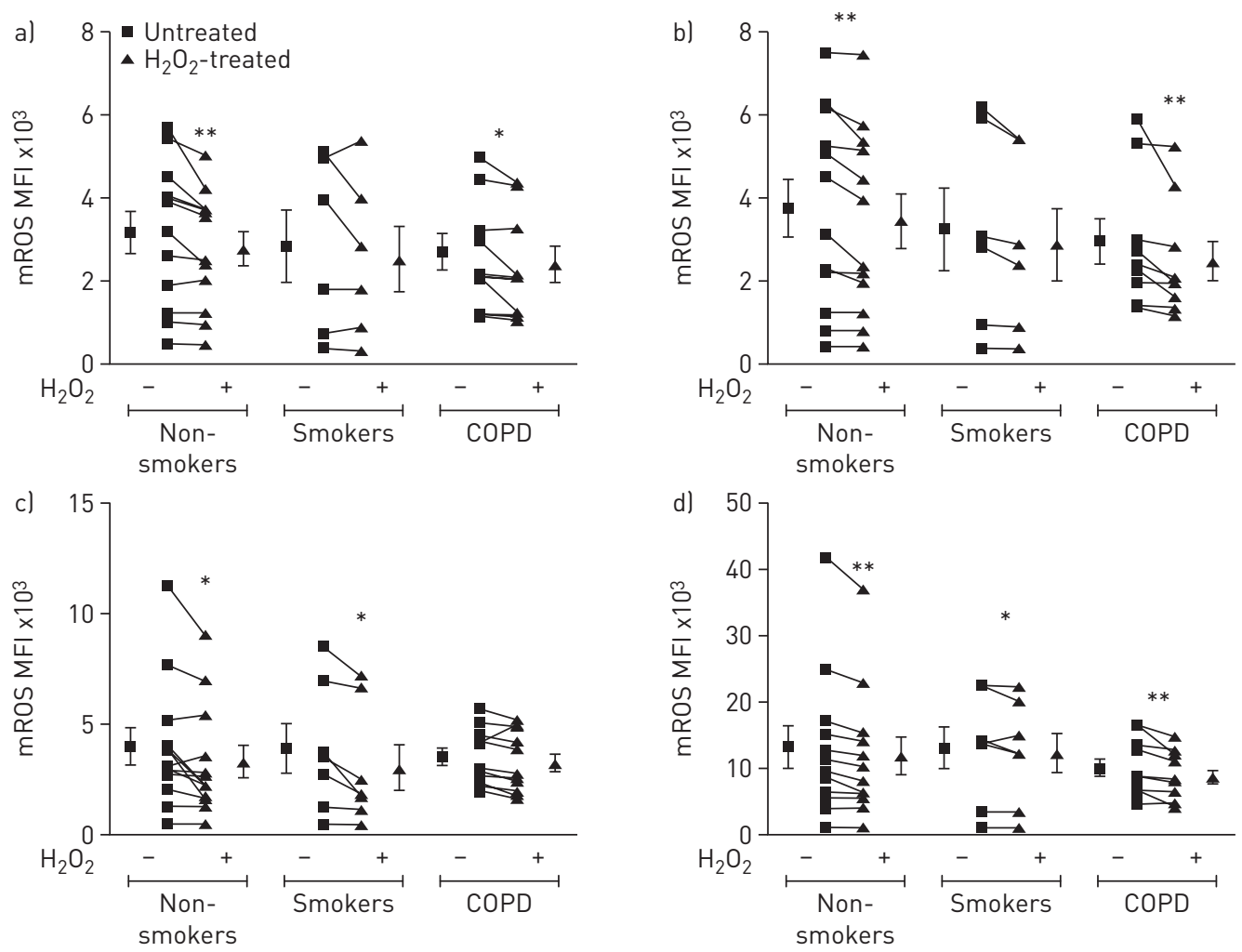

FIGURE 6 Exogenous oxidative stress decreases mitochondrial reactive oxygen species (mROS) production in macrophages. Macrophages differentiated in either macrophage-colony stimulating factor $(M-M \varphi)(a, b)$ or granulocyte macrophage-colony stimulating factor $(G-M \varphi)(c, d)$ from non-smokers ( $n=12)$, smokers without chronic obstructive pulmonary disease (COPD) ( $n=7-9$ ) and COPD patients ( $n=9-11$ ) were treated with $200 \mu \mathrm{M}$ hydrogen peroxide $\left(\mathrm{H}_{2} \mathrm{O}_{2}\right)$ for $24 \mathrm{~h}$, then co-cultured with fluorescently labelled Haemophilus influenzae $(\mathrm{a}, \mathrm{c})$ or Streptococcus pneumoniae (b, d) bacteria for $4 \mathrm{~h}$, after which mROS was measured by flow cytometry. Data are presented as individual data points and as mean \pm SEM of untreated or $\mathrm{H}_{2} \mathrm{O}_{2}$-treated cells. ${ }^{*}$ : $p<0.05$; **: $\mathrm{p}<0.01$ untreated versus $\mathrm{H}_{2} \mathrm{O}_{2}$.

S. pneumoniae $(\mathrm{p}<0.05)$ by COPD macrophages compared to non-smoker macrophages. However, there was no difference in the percentage of macrophages from healthy subjects or COPD patients that were able to phagocytose. These data suggest that while all macrophages are able to undergo the process of phagocytosis, it is the amount of bacteria, as measured by MFI, that can be consumed that is reduced in COPD. Importantly, there was no significant decrease in phagocytosis in smoker macrophages compared to those of non-smokers, although there was a trend towards decreased phagocytosis of $H$. influenzae with $\mathrm{G}-\mathrm{M} \varphi(\mathrm{p}=0.08)$, indicating that it is the disease rather than smoking history that determines this defect. These data confirm our previous observations [11], but we now show that differentiation of macrophages in M-CSF also leads to an aberrant macrophage phenotype in COPD, suggesting that this effect is not due to culture conditions alone but is potentially inherent in monocyte precursors. Therefore, this systemic defect further contributes to the reduced clearance of bacterial pathogens by macrophages in the lungs and may account for increased bacterial colonisation and the concomitant decline in lung function observed in COPD. In addition, the increased rates of pneumococcal bacteraemia in COPD may also be influenced by impaired function of blood monocytes and splenic macrophages [33]. Potential roles for defective circulating monocyte function in COPD comorbidities could be an area for future study.

In more developed nations, most COPD cases are due to cigarette smoking. This introduces high levels of oxidative stress into the lungs [34], which could be a contributing factor to the decreased function of COPD macrophages. To test this, we applied exogenous oxidative stress in the form of $\mathrm{H}_{2} \mathrm{O}_{2}$ to macrophages at a physiologically relevant concentration for $24 \mathrm{~h}$ [35]. $\mathrm{H}_{2} \mathrm{O}_{2}$ is released from activated inflammatory and structural cells, and is a component of cigarette smoke and air pollution [36]. We showed that exogenous oxidative stress caused a reduction in phagocytosis in both healthy and COPD alveolar macrophages and in both $\mathrm{G}-\mathrm{M} \varphi$ and $\mathrm{M}-\mathrm{M} \varphi$ from non-smokers, indicating that exposure to high levels of oxidative stress in the lungs could be a factor that influences defective macrophage phagocytosis in COPD. Interestingly, MDM from smokers without COPD did not respond to exogenous oxidative 

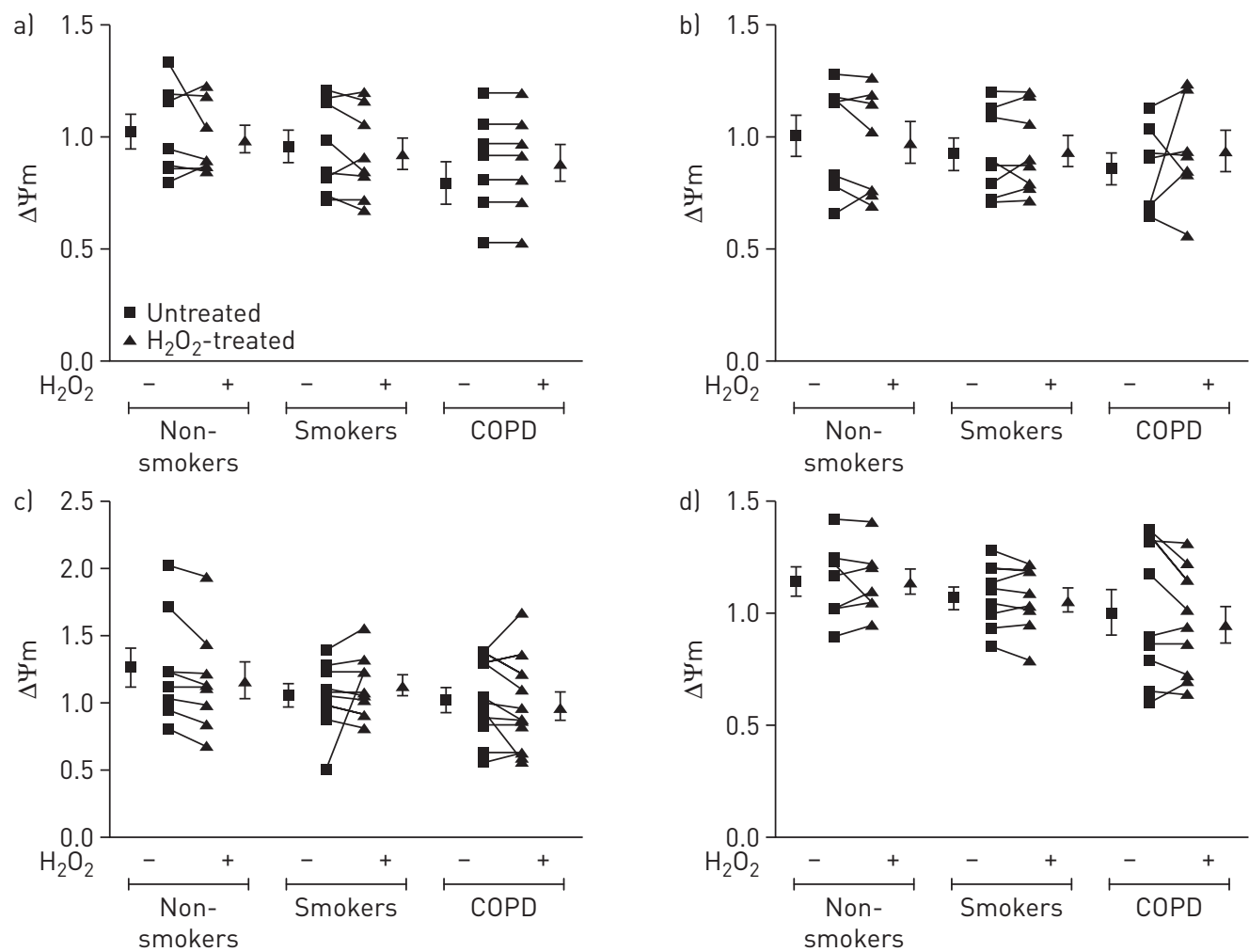

FIGURE 7 Exogenous oxidative stress does not affect mitochondrial membrane potential $(\Delta \Psi \mathrm{m})$ in macrophages. Macrophages differentiated in either macrophage-colony stimulating factor $(M-M \varphi)(a, b)$ or granulocyte macrophage-colony stimulating factor $(G-M \varphi)(c, d)$ from non-smokers $(n=8)$, smokers $(n=8-9)$ and COPD patients (n=8-11) were treated with $200 \mu \mathrm{M}$ hydrogen peroxide $\left(\mathrm{H}_{2} \mathrm{O}_{2}\right)$ for $24 \mathrm{~h}$, then co-cultured with fluorescently labelled Haemophilus influenzae (a, c) or Streptococcus pneumoniae (b, d) bacteria for $4 \mathrm{~h}$, after which $\Delta \Psi \mathrm{m}$ was measured by flow cytometry. Data are presented as individual data points and as mean \pm SEM of untreated or $\mathrm{H}_{2} \mathrm{O}_{2}$ treated cells.

stress, which could indicate a protective mechanism within smoker cells, such as increased expression of antioxidants. This is important because we have already demonstrated the role of Nrf2 in COPD [37].

We studied this further, and showed that macrophages cultured in the absence of exogenous oxidative stress showed no baseline differences in mROS or $\Delta \Psi \mathrm{m}$ between patient groups at the early time point studied. However, when the cells were analysed after phagocytosis of $H$. influenzae, both COPD MDM phenotypes showed increased levels of mROS and reduced $\Delta \Psi \mathrm{m}$, whereas macrophages from control subjects showed no change compared to baseline. After phagocytosis of $S$. pneumoniae, there was a similar increase in mROS levels in $\mathrm{M}-\mathrm{M} \varphi$, but not G-M $\varphi$, from COPD patients, and there was no change in $\Delta \Psi \mathrm{m}$, indicating a differential response to bacterial species. One caveat with these data is that extracellular fluorescence could not be quenched and therefore there may have been some contribution from extracellular bacteria to the response. Nevertheless, the differential responses from the different macrophage phenotypes may reflect alternative mechanisms for deriving ATP. M1 macrophages utilise a glycolytic pathway, whereas M2 macrophages utilise oxidative phosphorylation [38], an effect mirrored by $\mathrm{G}-\mathrm{M} \varphi$ and $\mathrm{M}-\mathrm{M} \phi$ respectively [39].

ROS induces damage by oxidising proteins and DNA, including mitochondrial DNA [40]. mROS released from mitochondria that are adjacent to phagolysosomes containing bacteria have been shown to be bactericidal in macrophages [41]; so, increasing the early production of mROS post phagocytosis may be a mechanism by which macrophages clear bacteria [42]. However, this increased mROS will then be scavenged by intracellular enzymes, including superoxide dismutase, to prevent damage to the cell [17]. The lack of a difference in mROS levels post phagocytosis in macrophages from healthy subjects suggests that if mROS are induced to assist in bacterial clearance, these oxidative species are rapidly quenched. The continued elevation in mROS in COPD macrophages suggests that the cells are unable to regulate mROS production, or that excessive levels of mROS are being generated which may overwhelm the endogenous antioxidant enzymes. It has been shown that levels of antioxidants, such as heme oxygenase-1, which is regulated by the transcription factor $\mathrm{Nrf}-2$, and superoxide dismutase, are decreased in COPD 
macrophages, which could contribute to the dysregulation of mROS seen here [43, 44]. Recently, we demonstrated that the Nrf-2 activator sulforophane was able to restore both non-opsonic and opsonic phagocytosis of $S$. pneumoniae in both alveolar macrophages and MDMs from COPD patients, further supporting the pivotal role of ROS in driving the defects in macrophage responsiveness to pathogens [37]. We have also identified chronic oxidative stress in alveolar macrophages from COPD patients [45] and our observations of intrinsic alterations in mitochondrial function and mROS generation in COPD MDMs could result in the chronic oxidative stress observed in COPD alveolar macrophages in vivo. The data presented in the current study complement these findings in a separate cohort of subjects and suggest that intrinsic mitochondrial function could drive both phagocytic defects and the oxidative stress that leads to this.

Excess levels of oxidants within the cell can cause damage to cellular components and induce apoptosis [17]. Therefore, following phagocytosis, increased mROS in COPD macrophages may alter the capacity of the cell to phagocytose subsequently, and contribute to the defective phagocytic pattern of "early satiety" seen in COPD. Exactly why the mitochondria are producing excessive ROS is unclear; however, this study shows a decreased $\Delta \Psi \mathrm{m}$ indicative of unhealthy mitochondria [20]. Excessive elevated mROS generated following phagocytosis in COPD macrophages may lead to the generation of pro-inflammatory cytokines due to activation of the inflammasome and transcription factors, and, further, to cell damage in COPD [17].

It has previously been shown that mROS is elevated in alveolar macrophages from COPD patients at baseline, but not following in vitro infection with $S$. pneumoniae [45]. This differs from our findings in MDMs, but may suggest that macrophages from the lungs, which will already have been exposed to lung bacteria, are primed to have elevated mROS, whereas blood macrophages require priming by exposure to bacteria to unmask the intrinsic mitochondrial defect we describe, and subsequently display increased oxidative stress. Further analysis of mitochondrial function in alveolar macrophages and MDMs is warranted to understand this complex processes.

Having established that mitochondrial function is abnormal in COPD macrophages, it was of interest to study whether exogenous oxidative stress was acting by altering mitochondrial function within macrophages. mROS and $\Delta \Psi \mathrm{m}$ were measured in MDMs pretreated with $\mathrm{H}_{2} \mathrm{O}_{2}$. At baseline, $\mathrm{H}_{2} \mathrm{O}_{2}$ had no effect on either aspect of mitochondrial function, but after phagocytosis, $\mathrm{H}_{2} \mathrm{O}_{2}$ caused a decrease in mROS in both $\mathrm{G}-\mathrm{M} \varphi$ and $\mathrm{M}-\mathrm{M} \varphi$ from non-smokers and COPD patients. This response may be due to exogenous oxidative stress reducing endogenous oxidative stress through alteration of the mROS/ antioxidant balance within the cell in order to limit the damage caused, or due to damage to the mitochondria itself, reducing cellular function. Alterations in mitochondrial function might lead to changes in metabolic balance of the cell and energy generation. One possible outcome from this could be changes in the phagocytic process, possibly via alterations in the dynamics of the cytoskeleton. Further, mitochondrial ROS is utilised in the killing of bacteria inside the cell, and so dysfunctional ROS production may alter the cells ability to react appropriately to a bacterial pathogen. Although targeting mitochondrial defects is difficult, it is a potential therapeutic approach [46].

In summary, both alveolar macrophages and $\mathrm{G}-\mathrm{M} \varphi$ and $\mathrm{M}-\mathrm{M} \varphi$ macrophage phenotypes from COPD patients demonstrate reduced phagocytosis of airway pathogens, which provides further support for the theory that there is an inherent circulating phagocytic defect in monocytes in disease. The reduction in phagocytosis was associated with dysregulation of mitochondrial function and intracellular mROS generation. Targeting mitochondria represents a treatment option for COPD, which may reverse the defective phagocytosis and reduce exacerbations in this disease.

Author contributions: Conception and design: K.B.R. Belchamber, L.E. Donnelly, P.J. Barnes, J.A. Wedzicha, M.K. Whyte, D.H. Dockrell, I. Kilty and M.J. Robinson. Acquisition of samples: K.B.R. Belchamber, C.M. Batista, R. Singh and J.A. Wedzicha. Performance of experiments: K.B.R. Belchamber and C.M. Batista. Analysis and interpretation of data: K.B.R. Belchamber and L.E. Donnelly. Manuscript preparation: K.B.R. Belchamber and L.E. Donnelly. All authors approved the final manuscript.

Conflict of interest: K.B.R. Belchamber reports grants from MRC during the conduct of the study. R. Singh has nothing to disclose. C.M. Batista reports grants from the National Institute for Health Research during the conduct of the study; and reports grants from Cempra Pharmaceuticals, lecture fees and educational presentations, outside the submitted work. M.K. Whyte reports grants from MRC during the conduct of the study; and reports grants for travel from Boehringer Ingelheim, outside the submitted work. D.H. Dockrell reports grants from MRC and Wellcome Trust during the conduct of the study; and grants from GSK, advisory board membership for Lilly and ViiV, non-financial support from Novartis, and other funding from AstraZeneca, MedImmune, RedX Pharmaceuticals, Sygnature Discovery, Pfizer and GSK, outside the submitted work. I. Kilty is an employee of Pfizer and holds stocks in Pfizer. M.J. Robinson is an employee of MedImmune and holds stocks in MedImmune. J.A. Wedzicha reports grants from GSK and Johnson and Johnson, other funding from Novartis, Boehringer Ingelheim, AstraZeneca and GSK, and grants from GSK, AstraZeneca, Boehringer Ingelheim and Novartis, outside the submitted work. P.J. Barnes has nothing to disclose. L.E. 
Donnelly reports grants from MRC during the conduct of the study; and has grants pending from Cempra Inc., AstraZeneca and Boehringer Ingelheim, outside the submitted work.

Support statement: This study was funded by the Medical Research Council (MRC) and the Association of the British Pharmaceutical Industry (ABPI) though support for the MRC-ABPI COPD-MAP consortium (G1001367/1). This study was supported by the National Institute for Health Research (NIHR) Respiratory Disease Biomedical Research Unit at the Royal Brompton and Harefield NHS Foundation Trust and Imperial College London. Funding information for this article has been deposited with the Crossref Funder Registry.

\section{References}

$1 \quad$ Barnes PJ, Kleinert S. COPD - a neglected disease. Lancet 2004; 364: 564-565.

2 Barnes PJ. Chronic obstructive pulmonary disease. N Engl J Med 2000; 343: 269-280.

3 Wilkinson TM, Patel IS, Wilks M, et al. Airway bacterial load and FEV 1 decline in patients with chronic obstructive pulmonary disease. Am J Respir Crit Care Med 2003; 167: 1090-1095.

4 Donaldson GC, Seemungal TAR, Bhowmik A, et al. Relationship between exacerbation frequency and lung function decline in chronic obstructive pulmonary disease. Thorax 2002; 57: 847-852.

5 Lindberg A, Eriksson B, Larsson LG, et al. Seven-year cumulative incidence of COPD in an an age-stratified general population sample. Chest 2006; 129: 879-885.

6 Simpson JL, Baines KJ, Horvat JC, et al. COPD is characterized by increased detection of Haemophilus influenzae, Streptococcus pneumoniae and a deficiency of Bacillus species. Respirology 2016; 21: 697-704.

7 Kopf M, Schneider C, Nobs SP. The development and function of lung-resident macrophages and dendritic cells. Nat Immunol 2015; 16: 36-44.

8 Berenson CS, Garlipp MA, Grove LJ, et al. Impaired phagocytosis of nontypeable Haemophilus influenzae by human alveolar macrophages in chronic obstructive pulmonary disease. J Infect Dis 2006; 194: 1375-1384.

9 Hodge S, Hodge G, Scicchitano R, et al. Alveolar macrophages from subjects with chronic obstructive pulmonary disease are deficient in their ability to phagocytose apoptotic airway epithelial cells. Immunol Cell Biol 2003; 81: 289-296.

10 Wrench C, Belchamber KBR, Bercusson A, et al. Reduced clearance of fungal spores by COPD GM-CSF and M-CSF derived macrophages. Am J Respir Cell Mol Biol 2018; 58: 271-273.

11 Taylor AE, Finney-Hayward TK, Quint JK, et al. Defective macrophage phagocytosis of bacteria in COPD. Eur Respir J 2010; 35: 1039-1047.

12 Lacey DC, Achuthan A, Fleetwood AJ, et al. Defining GM-CSF- and macrophage-CSF-dependent macrophage responses by in vitro models. J Immunol 2012; 188: 5752-5765.

13 Cai Y, Sugimoto C, Arainga M, et al. In vivo characterization of alveolar and interstitial lung macrophages in rhesus macaques: implications for understanding lung disease in humans. J Immunol 2014; 192: 2821-2829.

14 Perez-Rial S, del Puerto-Nevado L, Terron-Exposito R, et al. Role of recently migrated monocytes in cigarette smoke-induced lung inflammation in different strains of mice. PLoS One 2013; 8: e72975.

15 Retamales I, Elliott WM, Meshi B, et al. Amplification of inflammation in emphysema and its association with latent adenoviral infection. Am J Respir Crit Care Med 2001; 164: 469-473.

16 Barnes PJ. Inflammatory mechanisms in patients with chronic obstructive pulmonary disease. J Allergy Clin Immunol 2016; 138: 16-27.

17 Aravamudan B, Thompson MA, Pabelick CM, et al. Mitochondria in lung diseases. Expert Rev Respir Med 2013; 7: 631-646.

18 Ballweg K, Mutze K, Konigshoff $\mathrm{M}$, et al. Cigarette smoke extract affects mitochondrial function in alveolar epithelial cells. Am J Physiol Lung Cell Mol Physiol 2014; 307: L895-L907.

19 Wiegman $\mathrm{CH}$, Michaeloudes C, Haji G, et al. Oxidative stress-induced mitochondrial dysfunction drives inflammation and airway smooth muscle remodeling in patients with chronic obstructive pulmonary disease. J Allergy Clin Immunol 2015; 136: 769-780.

20 Han MK, Huang YJ, Lipuma JJ, et al. Significance of the microbiome in obstructive lung disease. Thorax 2012; 67: 456-463.

21 Puente-Maestu L, Perez-Parra J, Godoy R, et al. Abnormal mitochondrial function in locomotor and respiratory muscles of COPD patients. Eur Respir J 2009; 33: 1045-1052.

22 Barnes PJ. Mediators of chronic obstructive pulmonary disease. Pharmacol Rev 2004; 56: 515-548.

23 Hara H, Kuwano K, Araya J. Mitochondrial quality control in COPD and IPF. Cells 2018; 7:86.

24 Bialas AJ, Sitarek P, Milkowska-Dymanowska J, et al. The role of mitochondria and oxidative/antioxidative imbalance in pathobiology of chronic obstructive pulmonary disease. Oxid Med Cell Longev 2016; 2016: 7808576.

25 Bewley MA, Belchamber KB, Chana KK, et al. Differential effects of p38, MAPK, PI3K or Rho kinase inhibitors on bacterial phagocytosis and efferocytosis by macrophages in COPD. PLoS One 2016; 11: e0163139.

26 Chana KK, Fenwick PS, Nicholson AG, et al. Identification of a distinct glucocorticosteroid-insensitive pulmonary macrophage phenotype in patients with chronic obstructive pulmonary disease. J Allergy Clin Immunol 2014; 133: 207-216.

27 Dockrell DH, Lee M, Lynch DH, et al. Immune-mediated phagocytosis and killing of Streptococcus pneumoniae are associated with direct and bystander macrophage apoptosis. J Infect Dis 2001; 184: 713-722.

28 Schindeline J, Argand-Carreras I, Frise E, et al. Fiji: an open-source platform for biological-image analysis. Nat Methods 2012; 9: 676-682.

29 Johansson A, Lundborg M, Skold CM, et al. Functional, morphological, and phenotypical differences between rat alveolar and interstitial macrophages. Am J Respir Cell Mol Biol 1997; 16: 582-588.

30 Winkler AR, Nocka KH, Sulahian TH, et al. In vitro modeling of human alveolar macrophage smoke exposure: enhanced inflammation and impaired function. Exp Lung Res 2008; 34: 599-629.

31 Izquierdo E, Cuevas VD, Fernandez-Arroyo S, et al. Reshaping of human macrophage polarization through modulation of glucose catabolic pathways. J Immunol 2015; 195: 2442-2451.

32 Murray PJ, Allen JE, Biswas SK, et al. Macrophage activation and polarization: nomenclature and experimental guidelines. Immunity 2014; 41: 14-20. 
33 Torres A, Blasi F, Dartois N, et al. Which individuals are at increased risk of pneumococcal disease and why? Impact of COPD, asthma, smoking, diabetes, and/or chronic heart disease on community-acquired pneumonia and invasive pneumococcal disease. Thorax 2015; 70: 984-989.

34 Barnes PJ. New concepts in chronic obstructive pulmonary disease. Annu Rev Med 2003; 54: 113-129.

35 Sies H. Hydrogen peroxide as a central redox signaling molecule in physiological oxidative stress: oxidative eustress. Redox Biol 2017; 11: 613-619.

36 Valavanidis A, Vlachogianni T, Fiotakis K. Tobacco smoke: involvement of reactive oxygen species and stable free radicals in mechanisms of oxidative damage, carcinogenesis and synergistic effects with other respirable particles. Int J Environ Res Public Health 2009; 6: 445-462.

37 Bewley MA, Budd RC, Ryan E, et al. Opsonic phagocytosis in chronic obstructive pulmonary disease is enhanced by Nrf2 agonists. Am J Respir Crit Care Med 2018; 198: 739-750.

38 Diskin C, Pålsson-McDermott EM. Metabolic modulation in macrophage effector function. Front Immunol 2018; 9: $270-270$.

39 Fabbri L, Calverley P, Izquierdo-Alonso J, et al. Roflumilast in moderate-to-severe chronic obstructive pulmonary disease treated with longacting bronchodilators: two randomised clinical trials. Lancet 2009; 374: 695-703.

40 Desch AN, Gibbings SL, Goyal R, et al. Flow cytometric analysis of mononuclear phagocytes in nondiseased human lung and lung-draining lymph nodes. Am J Respir Crit Care Med 2016; 193: 614-626.

41 West AP, Brodsky IE, Rahner C, et al. TLR signalling augments macrophage bactericidal activity through mitochondrial ROS. Nature 2011; 472: 476-U543.

42 Hall CJ, Sanderson LE, Crosier KE, et al. Mitochondrial metabolism, reactive oxygen species, and macrophage function-fishing for insights. J Mol Med 2014; 92: 1119-1128.

43 Maestrelli P, Paska C, Saetta M, et al. Decreased haem oxygenase-1 and increased inducible nitric oxide synthase in the lung of severe COPD patients. Eur Respir J 2003; 21: 971-976.

44 Mercado N, Thimmulappa R, Thomas CM, et al. Decreased histone deacetylase 2 impairs Nrf2 activation by oxidative stress. Biochem Biophys Res Commun 2011; 406: 292-298.

45 Bewley MA, Preston JA, Mohasin M, et al. Impaired mitochondrial microbicidal responses in chronic obstructive pulmonary disease macrophages. Am J Respir Crit Care Med 2017; 196: 845-855.

46 Prakash YS, Pabelick CM, Sieck GC. Mitochondrial dysfunction in airway disease. Chest 2017; 152: 618-626. 